\title{
Impact of socioeconomic factors on somatotype components in macedonian adolescents
}

\begin{abstract}
Objectives: The main objective of the study was to assess the impact of socioeconomic factors on somatotype components in Macedonian adolescents at the age 11 to 18years.

Methods: The study included 2388 adolescents (1236 males and 1152 females) from four urban cities in R. Macedonia. Participants were measured with standard equipment and measurement technique according to the International Biological Program. Ten anthropometric parameters were measured to assess the somatotype according to HeatCarter somatotyping method. The examinees filled out the questionnaire with the data on socioeconomic status, parent's education and employment.
\end{abstract}

Results: There were significant differences for endomorph component in male adolescents between those with parents with high and low level of education. There were significant differences for mesomorph component in males related to parents educational level. Ectomorph component had a higher value in male adolescents when mother is with low educational level and when mother and father are unemployed. There were significant differences for endomorph component in female adolescents in relation to all socioeconomic factors except for employment status of the father; mesomorph and ectomorph component in females were related to parents educational level.

Conclusion: Our findings suggest that socioeconomic factors may be related to somatotype components in Macedonian adolescents.

Keywords: adolescent, somatotype, socioeconomic status, parent, anthropometry
Volume 2 Issue 4 - 2016

\author{
Biljana Bojadzieva Stojanoska,' Natasa \\ Nakeva Janevska,' Niki Matveeva,' Biljana \\ Zafirova,' Elizabeta Chadikovska,' Serjoza \\ Gontarev ${ }^{2}$ \\ 'Institute of Anatomy, Ss. Cyril and Methodius University, \\ Macedonia \\ ${ }^{2}$ Faculty of Physical Education, sport and health, Ss. Cyril and \\ Methodius University, Macedonia
}

Correspondence: Biljana Bojadzieva Stojanoska, Associate professor at the Institute of Anatomy, Faculty of Medicine, Ss. Cyril and Methodius University, Skopje, Macedonia, 50 Dizija No.6, 1000, Skopje, Macedonia, Tel +38970551991, Email bojadzievab@gmail.com

Received: March 17,2016| Published: May 12, 2016
Abbreviations: SE, somatotype unit; SES, socioeconomic status; LSES, low socioeconomic status; MSES, middle socioeconomic status; HSES, high socioeconomic status; IBP, international biological program

\section{Introduction}

Anthropometric somatotyping is one of the methods which describes the body shape and composition. The term somatotype and it is three components (endomorh, mesomorph and ectomorph) were described in 1940 by Sheldon and his co-workers. ${ }^{1}$ Later Heat and Carter introduced the simplified method for somatotyping and in the last few decades it has been the most used for studying body physics variations in children, adolescents and adults among populations, age changes and sex differences. ${ }^{1}$ Somatotype is physical expression of long-term interaction between personal genotype and external factors. The study of body constitution and relations with socioeconomic factors that can influence growth in the period of childhood and adolescence is of great interest of researchers. It can contrubute to better understanding of variations in body shape in the adult period and understanding the factors responsible for these variations. ${ }^{2}$

Somatotype in adults is relatively stable and the most common factors that can influence on the changes in body shape and structure are the eating habits and physical activity, but in the period of childhood and adolescence somatotype changes because of the different time of puberty and sexual maturity. ${ }^{3-6}$ In many anthropological studies that have examined the growth and development in children and adolescents, the knowledge about changes in somatotype during growth has contributed to better understanding of sex and age differences and changes in body composition. ${ }^{7-12}$

Beside genetic factor that influences the dynamics of growth and development and biological structure of child's and adolescent's body socioeconomic factors are of great importance thus, we can conclude that interaction between genotype and external factors is a complex process..$^{13}$ By frequent anthropometric measurments and following of changes in the body composition and shape during the period of childhood and adolescence, the socioeconomic circumstances of living and the impact of socioeconomic factors on genetic potential for linear growth can be proven. According to some researchers growth and somatotype change having in mind different socioeconomic status and parents aducation and employment status has impact. ${ }^{11,14-17}$ Macedonia belongs to developing countries with a high percent of unemployed residents (34.9\% in 2007) and only $8 \%$ of people with high education. ${ }^{18}$ Although Macedonia has no problem with malnutrition, the World Bank reports 7\% of residents with low level of income, hence they cannot receive minimal calories intake. ${ }^{19}$ According to our knowledge there are no studies analyzing the impact of socioeconomic factors on body composition of Macedonian adolescent population. Therefore, the main objective of our research was to assess the impact of socioeconomic status, educational level and employment status of adolescent's parents on their body composition.

\section{Materials and methods}

\section{Participants}

The sample included 2388 adolescents from four urban different regions of R. Macedonia aged between 11 to 18years; 1236 males and 1152 females. Participants from selected schools and classes were 
informed about the objective of the study and their parents signed the informed consent for participation in the research. All adolescents were healthy at the time of this study. In order to avoid errors in the selection of the sample, volunteer students were not included. Some of the participants that did not answer some of the questions about SES and educational level and employment status of parents were excluded from statistical analysis. This study is a cross-sectional one using background questionnaire and anthropometric measurements. Every participant has his/her own anthropometric file with the basic information: name, gender, and date of birth, place of birth, date of examination and values of measured anthropometric parameters. The University Human Research Ethics Committee approved the experimental protocols.

\section{Anthropometry and somatotype measurement}

For evaluation of somatotype ten anthropometric variables were selected and measured according to the International Biological Program (IBP): body height, elbow diameter and knee diameter; body weight, four skinfolds (triceps, subscapular, supraspinale and calf); and two circumferences (arm and calf). The following standard anthropometric instruments were used: for measuring body height anthropometer by Martin, with $1 \mathrm{~mm}$ reading accuracy; decimal weight scale; "John Bull" caliper square for determination of skinfolds with pressure of $10 \mathrm{~g} / \mathrm{cm} 2$ and precision of $0.1 \mathrm{~mm}$; elastic band, also with $1 \mathrm{~mm}$ reading accuracy, for measuring circumferences; and caliper square for measuring of diameters with reading precision of $1 \mathrm{~mm}$ and weight scale for measuring body weight. Anthropometric measurements were made during school hours, not interrupting the lessons. Subjects were standing, facing ahead, and body height was measured as maximum distance from the floor to the highest point on the head. Shoes were off, both feet together, and arms at the sides. Heels, buttocks and upper back were in contact with the wall. Body height measurement can vary throughout the day, usually being higher in the morning, so to ensure reliability we measured height at the same time of the day.

Somatotype components were assessed using the Carter Heat somatotyping method. The anthropometric somatotype was calculated by the following equations: ${ }^{20}$

Endomorphy $=-0.7182+(0.1451 \times \mathrm{X})-(0.00068 \times \mathrm{X} 2)+$ $(0.0000014 \times X 3)$, where $X=($ sum of triceps, subscapular, and supraspinal $) \times(170.18 /$ height, $\mathrm{cm})$. Mesomorphy $=(0.858 \times$ humerus breadth $)+(0.601 \times$ femur breadth $)+(0.188 \times$ corrected arm girth $)$ + Postural Stability in Children 175 (0.161×corrected calf girth) $($ height $\times 0.131)+4.5$, where corrected arm and calf circumferences are the respective limb circumferences minus the triceps and medial calf skinfolds. Three equations were used to calculate ectomorphy according to the height weight ratio (HWR): If HWR is $\geq 40.75$ then ectomorphy $=(0.732 \times \mathrm{HWR})-28.58$; if HWR is less than 40.75 but greater than 38.25 , then ectomorphy $=(0.463 \times \mathrm{HWR})-17.63$; if HWR $\leq 38.25$, then ectomorphy $=0.1$.

\section{SE) (Table 1, $2 \& 4$ ).}

\section{Socioeconomic factors}

For measuring family wealth, the Family Affluence Scale (FAS) has been used, designed by WHO - Health Behaviour in School-Aged Children (HBSC), which was anonimously filled by the participants, Currie et al., ${ }^{21}$ The FAS scale is composed of four items about household's financial situation, including: car ownership, bedroom occupancy standards, holidays and home computers. Students were classified according to the summed score of the items, with the overall score being recorded to give values of FAS 1 (0-3) low SES, FAS $2^{4,5}$ middle and FAS $3^{6,7}$ high SES. Participants also gave information about the level of education and employment status of their parents.

\section{Statistical analysis}

The data were analyzed with descriptive statistics represented by measures of central tendency and its deviation (arithmetic mean value and standard deviation). The significant differences between groups, formed by a different level of factors were evaluate through LSD test by ANOVA, on significance level $p<0.05$. The statistical package for the social sciences (version 20.0, SPSS Inc, Chicago, IL) was used for all statistical analysis. Somatotype-Calculation and Analysis V1.1. Monte Goulding, Sweat Technologies, Mitchell Park, South Australia software was used to determine somatotypes.

\section{Results and discussion}

Descriptive statistics of somatotype components in relation to level of education and employment status of adolescents' parents and socioeconomic status in males are presented in Table 1-5. There were significant differences of endomorph component in male adolescents in relation to all socioeconomic factors except for fathers employment status $(\mathrm{p}<0.05)$. Endomorph component had higher values $3.88 \pm 1.83$ SE (somatotype unit) and $3.79 \pm 1.81 \mathrm{SE}$ in males whose mother and father had completed University, contrary to males who live with parents with primary school: $3.00 \pm 1.55 \mathrm{SE}$ and $3.19 \pm 1.84 \mathrm{SE}$ (Table $1 \&$ Table 3). Endomorph component also had higher values when mother is employed $3.71 \pm 1.82 \mathrm{SE}$ and low value when mother is unemployed $3.23 \pm 1.56 \mathrm{SE}$ (Table 2). In relation to socioeconomic status a significant difference was found only for endomorph component and it had higher values in those with high socioeconomic status $(3.69 \pm 1.78 \mathrm{SE})$, than those with low socioconomic status (3.25 $\pm 1.54 \mathrm{SE})$ (Table 5).

There were significant differences for mesomorph component in males related to parental educational level $(\mathrm{p}<0.05)$. Mesomorph component is dominant when adolescents' mother and father had University degree or have completed primary school and values were lower in those whose parents have completed high school (Table 1 \& Table 3). Ectomorph component had higher value (3.39 $\pm 1.54 \mathrm{SE})$ in male adolescents when mother had completed primary school than in those with University degree (2.89 $\pm 1.49 \mathrm{SE})$, and in those whose mother and father are unemployed (3.26 $\pm 1.52 \mathrm{SE}$ and $3.31 \pm 1.64 \mathrm{SE})$, contrary to those with employed parents $(2.95 \pm 1.56 \mathrm{SE}$ and $3.02 \pm 1.54$

Table I Descriptive statistics of somatotype components related to mothers' educational level in males

\begin{tabular}{|c|c|c|c|c|c|c|c|c|c|}
\hline & \multicolumn{2}{|c|}{ Primary } & \multicolumn{2}{|c|}{ High school } & \multicolumn{2}{|c|}{ University } & \multirow{2}{*}{$\mathbf{F}$} & \multirow{2}{*}{$\mathbf{p}$} & \multirow{2}{*}{$\begin{array}{l}\text { Post hoc pair waise } \\
\text { comparisons }\end{array}$} \\
\hline & Mean & SD & Mean & SD & Mean & SD & & & \\
\hline Endomorphy & 3.01 & 1.55 & 3.53 & 1.72 & 3,89 & I,83 & 19,48 & ,000 & $1 \& 2 ; 1 \& 3 ; 2 \& 3$ \\
\hline Mesomorphy & 3.91 & 1.3 & 3.59 & 1.51 & 3,92 & $\mathrm{I}, 44$ & 7,99 & ,000 & $1 \& 2 ; 2 \& 3$ \\
\hline Ectomorphy & 3.4 & 1.5 & 3.04 & 1.6 & 2,89 & 1,49 & 8,09 & ,000 & I\&2; I\&3 \\
\hline
\end{tabular}


Table 2 Descriptive statistics of somatotype components related to mothers' employment status in males

\begin{tabular}{lllllll}
\hline & \multicolumn{2}{l}{ Employed } & \multicolumn{2}{c}{ Unemployed } & \multirow{2}{*}{ F } & P \\
\cline { 2 - 5 } & Mean & SD & Mean & SD & & \\
\hline Endomorphy & $3.7 \mathrm{I}$ & $\mathrm{I} .82$ & 3.23 & $\mathrm{I} .56$ & 21.35 & 0 \\
Mesomorphy & 3.76 & $\mathrm{I} .5 \mathrm{I}$ & 3.75 & $\mathrm{I} .34$ & 0.04 & 0.848 \\
Ectomorphy & 2.95 & $\mathrm{I} .57$ & 3.27 & $\mathrm{I} .52$ & $\mathrm{II} .75$ & $0.00 \mathrm{I}$ \\
\hline
\end{tabular}

Table 3 Descriptive statistics of somatotype components related to fathers' educational level in males

\begin{tabular}{|c|c|c|c|c|c|c|c|c|c|}
\hline & \multicolumn{2}{|c|}{ Primary } & \multicolumn{2}{|c|}{ High school } & \multicolumn{2}{|c|}{ University } & \multirow{2}{*}{$\mathbf{F}$} & \multirow{2}{*}{$\mathbf{p}$} & \multirow{2}{*}{$\begin{array}{l}\text { Post hoc pair waise } \\
\text { comparisons }\end{array}$} \\
\hline & Mean & SD & Mean & SD & Mean & SD & & & \\
\hline Endomorphy & 3.19 & 1.84 & 3.48 & 1.69 & 3.79 & 1.81 & 7.06 & 0.001 & $1 \& 3 ; 2 \& 3$ \\
\hline Mesomorphy & 3.94 & 1.38 & 3.63 & 1.46 & 3.89 & 1.42 & 5.46 & 0.004 & $1 \& 2 ; 2 \& 3$ \\
\hline Ectomorphy & 3.31 & $1.6 \mathrm{I}$ & 3.07 & $\mathrm{I} .54$ & 2.99 & 1.57 & 1.93 & 0.146 & NS \\
\hline
\end{tabular}

Table 4 Descriptive statistics of somatotype components related to fathers' employment status in males

\begin{tabular}{lllllll}
\hline & \multicolumn{2}{l}{ Employed } & \multicolumn{2}{l}{ Unemployed } & \multirow{2}{*}{ F } & P \\
\cline { 2 - 5 } & Mean & SD & Mean & SD & & \\
\hline Endomorphy & 3.58 & $\mathrm{I} .75$ & 3.32 & 1.78 & 2.97 & 0.085 \\
Mesomorphy & 3.76 & $\mathrm{I} .45$ & 3.68 & 1.47 & 0.43 & 0.513 \\
Ectomorphy & 3.03 & $\mathrm{I} .54$ & $3.3 \mathrm{I}$ & $\mathrm{I} .64$ & 4.64 & 0.031 \\
\hline
\end{tabular}

Table 5 Descriptive statistics of somatotype components related to socioeconomic status in males

\begin{tabular}{|c|c|c|c|c|c|c|c|c|c|}
\hline & \multicolumn{2}{|l|}{ LSES I } & \multicolumn{2}{|c|}{ MSES2 } & \multicolumn{2}{|c|}{ HSES3 } & \multirow{2}{*}{$\mathbf{F}$} & \multirow{2}{*}{$\mathbf{p}$} & \multirow{2}{*}{$\begin{array}{l}\text { Post hoc pair waise } \\
\text { comparisons }\end{array}$} \\
\hline & Mean & SD & Mean & SD & Mean & SD & & & \\
\hline Endomorphy & 3.25 & 1.55 & 3.59 & 1.81 & 3.69 & 1.79 & 5.26 & 0.005 & $1 \& 2 ; 1 \& 3$ \\
\hline Mesomorphy & 3.73 & 1.38 & 3.7 & 1.49 & 3.86 & 1.45 & 1.42 & $0.24 I$ & NS \\
\hline Ectomorphy & 3.19 & 1.5 & 3.03 & 1.61 & 3.02 & $1.5 \mathrm{I}$ & I.I & 0.333 & NS \\
\hline
\end{tabular}

LSES'- low socioeconomic status

$\mathrm{MSES}^{2}$-middle socioeconomic status

HSES $^{3}$-high socioeconomic status

Descriptive statistics of somatotype components in relation to level of education and employment status of adolescents' parents and socioeconomic status in females are presented in Tables 6-10. There were significant differences of endomorph component in female adolescents in relation to all socioeconomic factors except for employment status of the father $(\mathrm{p}>0.05)$. Endomorph component had higher values in females whose mother and father have completed high school $(4.65 \pm 1.45 \mathrm{SE}$ and $4.58 \pm 1.44 \mathrm{SE})$, contrary to females who live with parents with completed primary school $(4.28 \pm 1.48$ SE and 4.24 \pm 1.52 SE) (Table $6 \&$ Table 8). Endomorph component had also higher value when mother is employed (4.55 $\pm 1.36 \mathrm{SE})$ and lower value when mother is unemployed (4.35 $\pm 1.47 \mathrm{SE}$ ) (Table $8)$. In relation to socioeconomic status a significant difference was found only for endomorph component and it had higher values in those with middle socioeconomic status $(4.58 \pm 1.46 \mathrm{SE})$ than in those with low socioconomic status $(4.23 \pm 1.44 \mathrm{SE})$ (Table 10). There were significant differences of mesomorph component in females related to parents' educational level $(\mathrm{p}<0.05)$. Mesomorph component was dominant when adolescents' mother and father had completed primary school $(3.46 \pm 1.18 \mathrm{SE}$ and $3.54 \pm 1.23 \mathrm{SE})$ and values were lower in those whose parents had University degree (2.89 $\pm 1.16 \mathrm{SE}$ and 2.87 $\pm 1.13 \mathrm{SE}$ ) (Table 6) (Table 8). There were significant differences of ectomorph component in female adolescents only in relation to educational level of parents $(p<0.05)$. Higher values of ectomorph component had those with both parents had completed University, and the lowest values were found in those whose parents had high school (Table 6) (Table 10).

There are a lot of studies according to which body growth and somatotypes change under socioeconomic circumstances of living, but there are few studies conducted on Macedonian population. In this study we confirmed the positive relation of some socioeconomic factors (socioeconomic status, parents' level of education and employment status) and somatotype components in Macedonian adolescent population aged 11 to 18 years. Rahmawati et al. ${ }^{15}$ Studied the differences of body height, weight and somatotypes between two groups of children and adolescents at the age of 7 to $15 y$ years from rural and urban regions in Indonesia. According to their study in 
both males and females from urban region of Yogyakarta from wellsituated families endomorph component was dominant, compared to those from rural region of Bantul, who were more mesomorphic, especially those from families with lower socioeconomic status and over the age of twelve. Also ectomorph component had higher values in both sexes in children from rural region of Indonesia. In the study of Turkish scientists Can Pelin et al. about the impact of socioeconomic conditions on somatotype components in healthy male adolescents at the age of 11, from Ankara, Turkey, adolescents from families with high SES and parents with high educational level were more endomorphs. Those who live in middle SES had lower mesomorph values than those with low or high SES. According to them the impact of educational level on body shape is higher than socioeconomic living conditions. ${ }^{16} \mathrm{M}$. Jesus Munoz states that there are important differences in body shape and composition especially in males in relation to SES and level of education of father and employment status of mother. ${ }^{17}$ The most variable components were endomorph and mesomorph, with higher values in those adolescents who live in lower, and ectomorph is dominant in adolescents who live in high socioeconomic circumstances. Their results of body shape showed to be more constant in females in relation to SES. ${ }^{17}$ Similar results were presented in the studies of Dibamani Singh et al. and Teles Julia et al. ${ }^{22}$ according to whom endomorph component had higher values in adolescents from middle SES compared to those with high SES. ${ }^{14,22}$ In our study we found a great variability of all three components in relation to educational level of both parents of male adolescents. They had significantly higher values for endomorph and mesomorph components when parents had high education. Ectomorph component was significantly dominant in those male adolescents with low educated mother but we did not find a significant difference in relation to fathers' education for ectomorph component. Endomorph and ectomorph component were significantly different; endomorph values were higher when the mother of male adolescents was employed and lower when the mother was unemployed. Simillarly results were obtained in males whose father was unemployed. SES had impact only on endomorph component which had higher values when SES was high in males. Simillar results we got for somatotype components of female Macedonian adolescents in relation to socioeconomic factors. The most significant differences for all three components were found in females in relation to educational level and employment status of mother, and there were no differences in relation to employment status of father. Our results have shown that mothers' educational level and employment status had higher impact on body composition in both males and females than father's education and employment and SES. This might be a result of higher influence of the mother on eating habits as well as of lifestyle of their adolescents. Those adolescents from parents who are unemployed are more exposed to physical activity and the monthy income is lower; hence they can not afford themselves fast food which is more caloric.

Table 6 Descriptive statistics of somatotype components related to mothers' educational level in females

\begin{tabular}{|c|c|c|c|c|c|c|c|c|c|}
\hline & \multicolumn{2}{|c|}{ Primary } & \multicolumn{2}{|c|}{ High school } & \multicolumn{2}{|c|}{ University } & \multirow{2}{*}{$\mathbf{F}$} & \multirow{2}{*}{$\mathbf{p}$} & \multirow{2}{*}{$\begin{array}{l}\text { Post hoc pair waise } \\
\text { comparisons }\end{array}$} \\
\hline & Mean & SD & Mean & SD & Mean & SD & & & \\
\hline Endomorphy & 4.28 & 1.49 & 4.65 & I.45 & 4.38 & 1.25 & 7.55 & 0.001 & $1 \& 2 ; 2 \& 3$ \\
\hline Mesomorphy & 3.46 & 1.19 & 3.11 & 1.33 & 2.9 & 1.16 & 15.9 & 0 & $1 \& 2 ; \mid \& 3 ; 2 \& 3$ \\
\hline Ectomorphy & 3.11 & 1.61 & 2.78 & 1.49 & 3.15 & 1.36 & 8.3 & 0 & $1 \& 2 ; 2 \& 3$ \\
\hline
\end{tabular}

Table 7 Descriptive statistics of somatotype components related to mothers' employment status in females

\begin{tabular}{llllllll}
\hline & \multicolumn{2}{c}{ Employed } & \multicolumn{2}{c}{ Unemployed } & \\
\cline { 2 - 5 } & Mean & SD & Mean & SD & & \\
\hline Endomorphy & 4.56 & 1.37 & 4.36 & 1.48 & 5.54 & 0.019 \\
Mesomorphy & 3.03 & 1.27 & 3.3 & 1.25 & 12.74 & 0 \\
Ectomorphy & 2.95 & 1.43 & 3.01 & 1.59 & 0.52 & 0.473 \\
\hline
\end{tabular}

Table 8 Descriptive statistics of somatotype components related to fathers' educational level in females

\begin{tabular}{|c|c|c|c|c|c|c|c|c|c|}
\hline & \multicolumn{2}{|c|}{ Primary } & \multicolumn{2}{|c|}{ High school } & \multicolumn{2}{|c|}{ University } & \multirow{2}{*}{$\mathbf{F}$} & \multirow{2}{*}{$\mathbf{p}$} & \multirow{2}{*}{$\begin{array}{l}\text { Post hoc pair waise } \\
\text { comparisons }\end{array}$} \\
\hline & Mean & SD & Mean & SD & Mean & SD & & & \\
\hline Endomorphy & 4.25 & 1.53 & 4.58 & 1.45 & 4.38 & 1.26 & 4.66 & 0.01 & $1 \& 2 ; 2 \& 3$ \\
\hline Mesomorphy & 3.54 & 1.23 & 3.16 & 1.31 & 2.87 & $\mathrm{I} .14$ & 16.5 & 0 & $|\& 2 ;| \& 3 ; 2 \& 3$ \\
\hline Ectomorphy & 3.02 & 1.56 & 2.89 & 1.53 & 3.14 & 1.4 & 3.36 & 0.035 & $2 \& 3$ \\
\hline
\end{tabular}


Table 9 Descriptive statistics of somatotype components related to fathers' employment status in females

\begin{tabular}{lllllll}
\hline & \multicolumn{2}{l}{ Employed } & \multicolumn{2}{l}{ Unemployed } & \multirow{2}{*}{ F } \\
\cline { 2 - 5 } & Mean & SD & Mean & SD & & \\
\hline Endomorphy & 4.49 & 1.41 & 4.26 & 1.3 & 3.62 & 0.057 \\
Mesomorphy & 3.09 & 1.27 & 3.22 & 1.2 & 1.54 & 0.216 \\
Ectomorphy & 2.99 & 1.5 & 3.08 & 1.47 & 0.48 & 0.491 \\
\hline
\end{tabular}

Table 10 Descriptive statistics of somatotype components related to socioeconomic status in females

\begin{tabular}{|c|c|c|c|c|c|c|c|c|c|}
\hline & \multicolumn{2}{|c|}{ LSES I } & \multicolumn{2}{|c|}{ MSES2 } & \multicolumn{2}{|c|}{ HSES3 } & \multirow{2}{*}{$\mathbf{F}$} & \multirow{2}{*}{$\mathbf{p}$} & \multirow{2}{*}{$\begin{array}{l}\text { Post hoc pairwaise } \\
\text { comparisons }\end{array}$} \\
\hline & Mean & SD & Mean & SD & Mean & SD & & & \\
\hline Endomorphy & 4.23 & $\mathrm{I} .44$ & 4.58 & 1.47 & 4.54 & 1.29 & 6.13 & 0.002 & I\&2; I\&3 \\
\hline Mesomorphy & 3.21 & 1.32 & 3.15 & 1.3 & 3.03 & 1.17 & 1.75 & 0.175 & NS \\
\hline Ectomorphy & 3.11 & 1.68 & 2.89 & $\mathrm{I} .47$ & 3 & 1.35 & 2.09 & 0.124 & NS \\
\hline
\end{tabular}

LSES'- low socioeconomic status

$M^{2} E^{2}$-middle socioeconomic status

HSES $^{3}$-high socioeconomic status

\section{Conclusion}

Somatotype in the period of adolescence give information not only about sex and age differences of body shape in this sensitive period of growth and development but also give information on body composition. Our study had a goal to examine one, until now, not investigated issue, to assess the impact of some socioeconomic factors on somatotype components of the population group of adolescents of both males and females in the Republic of Macedonia. According to our study socioeconomic factors are related to somatotype components, especially with endomorph and mesomorph component of somatotype of Macedonian adolescents. We can conclude that parents' educational level and employment status had some influence on body shape and composition. When determining the somatotype of Macedonian adolescents socioeconomic inequalities and sex should be considered.

\section{Acknowledgements}

None.

\section{Conflict of interest}

Author declares that there is no conflict of interest.

\section{References}

1. Carter JEL. The Heath-Carter somatotype method. 3rd ed. San Diego State University Syllabus Service, San Diego; 2002.

2. Tanner JM. Growth and maturation during adolescence. Nutr Rev. 1981;39(2):43-55.

3. Tanner JM, Whitehouse RH, Takaiski M. Standards from birth to maturity for height, weight, height velocity and weight velocity. Arch Dis Child. 1966;41(220):454-471

4. Tanner JM. Growth at adolescence; with a general consideration of the effects of hereditary and environmental factors upon growth and maturation from birth to maturity. Oxford: Blackwell Scientific Publications; 1962.

5. Gakhar I, Malik SL. Age changes and sex differences in somatotypes among Jats of Delhi. Anthropol. 2002;4(2):115-125.
6. Widiyani T, Suryobroto B, Budiarti S, et al. The Growth of Body Size and Somatotype of Javanese Children Age 4 to 20Years. J Biosci. 2001;18(4):182-192.

7. Rogol AD, Clark PA, Roemmich JN. Growth and pubertal development in children and adolescents: effects of diet and physical activity. Am J Clin Nutr. 2000;72(2 Suppl):521-528.

8. Heath BH, Carter JE. Growth and somatotype patterns of Manus children, Territory of Papua and New Guinea: Application of a modified somatotype method to the study of growth patterns. Am J Phys Anthrop. 1971;35(1):49-67.

9. Walker RN. Standards for somatotyping children: II. The prediction of somatotyping ponderal index from childrens growth data. Ann Hum Biol. 1974;1(3):289-299.

10. Oyewale AA, Ojo SA, Adebisi SS, et al. The study of anthropometric variables on growth and development of school children in Zaria, Nigeria. Asian J Med Sci. 2010;2(4):185-189.

11. Mohan Das B, Roy SK. Age changes in the anthropometric and body composition characteristics of the Bishnupriya Manipuris of Cachar district, Assam. Adv Biosci Biotechnol. 2010;1(2):122-130.

12. Nikolova M, Akabaliev V, Sivkov S, et al. Body composition of children and adolescents from Plovdiv. In: Proceedings of the Balkan scientific conference of biology. Plovdiv (Bulgaria). 2005:150-158.

13. Tanner JM. Auxology. In: Kappy MS, Blizzard RM, editors. The diagnosis and treatment of endocrine disorders in childhood and adolescence. 4th ed. Springfield, IL: Charles C. Thomas; 1994. p. 137192.

14. Singh LD. Somatotypes of the Affluent and Non-affluent Meitei boys of Manipur, India. Anthropol. 2011;13(1):9-16.

15. Rahmawati TN, Hastuti J, Ashizawa K. Growth and somatotype of urban and rural Javanese children in Yogyakarta and Bantul, Indonesia. Anthropol Sci. 2004;112:99-108.

16. Pelin C, Ozener B, Kurkuoglu A, et al. Effect of living conditions on somatotype components of young individuals belonging to different socioeconomic strata: a preliminary study. Eur J Anthropol. 2010;1(1):26-32.

17. Cachón MJ, Salces I, Arroyo M, et al. Body shape in relation to socioeconomic status in young adults from Basque country. Coll Antropol. 2007;31(4):963-968. 
18. Josevska E. Health of the population of Republic of Macedonia. Skopje: Institute of Public Health of the Republic of Macedonia; 2010.

19. Currie C, Zanotti C, Morgan A, et al. Social determinants of health and well-being among young people. Health Behaviour in School-aged Children (HBSC) study: international report from the 2009/2010 survey. WHO Regional Office for Europe, Copenhagen; 2012.

20. Carter JEL, Heath BH. The Heat-Carter somatotype method. In: Carter JEL, Heath BH, editors. Somatotyping: Development and Applications. New York: Cambridge University press; 1990. p. 352-353.
21. Currie CE, Elton RA, Todd J, et al. Indicators of socio-economic status for adolescents: the WHO health behaviour in school-aged survey. Health Educ Res. 1997;12(3):385-397.

22. Teles J, Barrigas C, Fragoso I, et al. Multivariate analysis of variance: an application to somatotype components of children from Lisbon. In: Teles J, Barrigas C, editors. Bulletin of the International Statistical Institute, 56th Session. International Statistical Institute, Lisbon, Portugal; 2007;LXII:5796-5799. 